\title{
Do overarching mitigation objectives dominate transport-specific targets in the EU?
}

\author{
Frédéric Ghersi ${ }^{a, b}$ \\ Simon McDonnellc \\ Olivier Sassia

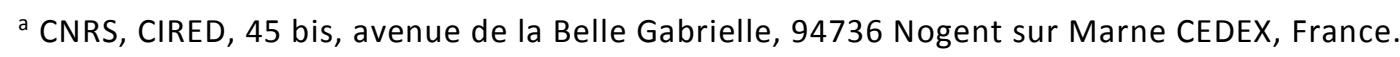 \\ b Corresponding author. Email: ghersi@centre-cired.fr. Phone: +331439473 73. Fax: +331439473 \\ 70.
}

c Office of Policy Research, City University of New York (CUNY), 555 West 57th Street, New York, NY 10019.

\begin{abstract}
This research investigates if the stringent 2020 and 2050 overarching $\mathrm{CO}_{2}$ mitigation objectives set out by the European Union dominate its 2010 to 2020 targets specific to the transportation arena, specifically its biofuel penetration objectives and gram $\mathrm{CO}_{2}$ per kilometre emission caps. Using a dynamic recursive general equilibrium model, IMACLIM-R, we demonstrate that these overarching targets do not dominate the interim transportation targets when the carbon policy triggering compliance with the mitigation objectives boils down to the theoretical least-cost option of uniform carbon pricing. Ground transportation is confirmed as quite insensitive to high carbon prices, even when such prices are applied over a long term. It is tempting to conclude that pursuing the mitigation objectives specific to transportation will impose unnecessary costs. However, because of the second best conditions prevailing in actual economies, and of the risk of lock-in in carbon intensive trajectories, we conclude with the urgent need for some ambitious transport-specific policy design research agenda.
\end{abstract}

\section{Keywords}

EU climate policy; EU transportation policy. 


\section{Acknowledgments}

The authors gratefully acknowledge funding by the European Commission under the TranSust.Scan Project. A. Vogt-Schilb, CIRED, provided useful comments on a preliminary version and precious support at the time of revision. Two anonymous reviewers significantly helped to improve the paper through their remarks and suggestions. The final document is the sole responsibility of the authors.

\section{Introduction}

The European Union developed two important and related strategies concerning transportation and sustainability in 2001. The first, the White Paper on Transport, investigated the trends in transport for the coming decade and proposed a number of policy packages (CEC, 2001a). The second, the Sustainable Development Strategy (SDS), articulated, for the first time, an integrated EU policy on sustainability (CEC, 2001b). Recent reviews of both documents reaffirmed and extended the commitments of European policymakers in these areas. The White Paper on Transport was central to European policymaking in this area for the period up to 2010 and received considerable attention from policymakers and researchers alike. It has recently been replaced by a new strategy for the period up to 2020 (CEC, 2011 a). However, relatively little academic focus has centred on the potential impacts of the SDS on transportation trends in the European Union. Its overriding environmental objective is to cap the increase in global temperature rise to $2^{\circ} \mathrm{C}$ above pre-industrial levels by the end of this century. In order to achieve this goal, the European Union (EU) has committed itself to stringent interim targets in carbon dioxide $\left(\mathrm{CO}_{2}\right)$ emissions reductions by 2020 and 2050 respectively. The target is to reduce EU emissions by $20 \%$ compared to 1990 levels in the absence of any international agreement by 2020 and by 60 to $80 \%$ by 2050 (CEU, 2007). This 2050 target was subsequently raised to an 80 to $95 \%$ reduction objective in late 2009 through a European Council stated objective within the context of a broader international agreement (DGE, 2011). More recently, the European Commission adopted its “Energy Roadmap 2050" as a basis for developing a long-term European energy use framework that also enshrines the 80-95\% target (CEC, 2011b). It is clear that the pursuit and achievement of these long term targets will, almost by necessity, impact on future trends in European transportation.

In this paper, we investigate the impact of these overarching carbon constraints on the more focused short-term transportation objectives outlined in the SDS. To do this, we project the state and trends of European transportation up to 2050 in a business-as-usual or reference scenario, and compare it to an ambitious carbon-pricing scenario that proxies for the 2020 and 2050 emissions targets, at least at their pre-2009 levels. ${ }^{1}$ The reference and carbon-constrained scenarios are projections of the global dynamic recursive computable general equilibrium model IMACLIM-R. The model has specifically been devel- 
oped by CIRED to guarantee a full consistency between macroeconomic and energy balances. Our purpose is to develop the above scenarios with the aim of exploring whether reaching both the interim $20 \%$ and the long-term $60 \%-80 \%$ reduction in $\mathrm{CO}_{2}$ emissions by 2020 and 2050 through standard carbon pricing necessarily 'dominates', i.e. implies compliance with, other targets specifically related to the transport sphere outlined in the SDS-and develop a better understanding as to why it does or does not.

The outline of the paper is as follows: section 1 presents some key transportation trends in the European Union as it stands, it also outlines some of the problems associated with transport, and investigates some of the key Europe-wide policy responses developed by policymakers. Section 2 briefly reviews the SDS, paying particular attention to its role in relation to transport. Section 3 presents an overview of the IMACLIM-R model and reports key assumptions and general results of the baseline and policy projections. Section 4 focuses on transport and tests the hypothesis outlined above. Finally, section 5 concludes with some policy observations.

\section{Transportation trends in the European Union}

The growth in demand for road transportation in Europe has been rapid in recent decades. European policymakers turned towards analyzing and mitigating the negative impacts of these trends with the publication of the first White Paper on transportation in 1992. But by 2001, the number of cars in the EU had trebled over 1970 levels to almost 175 million and continued to grow by about 3 million cars a year at the turn of the century (CEC, 2001a). In tandem with this, personal mobility on the continent doubled (CEC, 2006) and increased by another 7\% in the period up to 2008 (CEC, 2011c). As a result, between 1995 and 2004 road transportation grew by 19\% for passenger cars and by 35\% for freight movements (measured by passenger-kilometres and tonne-kilometres respectively), continuing a long seen trend. Only with the economic crisis, beginning in 2008, did these trends slow (CEC, 2011c). The impact on Europe's oil consumption and emissions of greenhouse gases is significant. Transport accounts for over $30 \%$ of final energy consumption in the EU. By 2006 the road transportation sector accounted for $44 \%$ of total freight transport (tonne kilometres) and almost $85 \%$ of total passenger transport (passenger kilometres) (CEC, 2006). The White Paper Midterm Review (CEC, 2006) notes that the private car accounts for three-quarters of passenger transport while transport by bus and coach combined accounts for less than $10 \%$ (these latter modes have grown by a modest $5 \%$ over the last decade). As a result of such trends, private cars account for half of energy consumed by transport (EEA, 2012). Emissions from domestic transport contributed $21 \%$ of all $\mathrm{CO}_{2}$ emissions in Europe-one of the fastest-growing sectors; such emissions grew by $23 \%$ over the period 1990 to $2010 .^{2}$ With road transportation heavily dependent on oil (it accounted for 67\% of final European demand for oil in 2006 and 
by 2008 , over $95 \%$ of energy use in road transportation was made up of gasoline and diesel (CEC, 2011c)), it alone accounted for almost $85 \%$ of $\mathrm{CO}_{2}$ emissions from transport in 2006 (CEC, 2006). These trends have not changed markedly in the interim despite the economic crisis since 2008. They raised environmental concerns that, coupled with increased concerns about security of energy and institutional changes within the EU, have moved transportation towards the centre of the European policy agenda over the last two decades.

The European Commission has long recognised the economic costs of excessive growth in road transport demand (cf. e.g. CEC, 1992; CEC, 1993). It often results in congestion because of the public good nature of road space (Sterner, 2003). But the costs of road transport are not restricted to users of the infrastructure. Indeed, the external costs of road traffic congestion, ${ }^{3}$ were projected to more than double from $0.5 \%$ of EU gross domestic product (GDP) in 2001 by the end of the decade (CEC, 2001a). The recently published White Paper (CEC, 2011a; CEC, 2011c) estimated that congestion costs would reach $€ 200$ billion per annum by 2050 . The additional costs of road transportation also include accidents, road damage externalities and environmental costs. The latter costs consist of regional environmental effects (including barrier effects imposed by transportation infrastructure, ${ }^{4}$ acidification and noise) and air pollution (with both local and global impacts). This point is especially relevant given the increase in transport-related greenhouse gases (GHG) emissions and previously stated broader European commitments to the Kyoto Protocol and other initiatives to reduce GHG emissions, exemplified by programs such as the European Union Emissions Trading Scheme. Partly as a result of increasing emissions from road transport sources (up by $30 \%$ since 1990; CEC, 2007), many countries are now struggling to meet their commitments to comply with agreed Kyoto Protocol limits. ${ }^{5}$

Consequently, the focus of European policymakers in the area of transportation has widened from a primarily economic analysis, as per the first White Paper of 1992 (CEC, 1992), to encompass the other two spheres of sustainability, namely the environmental and social areas. This has been mirrored in the development of the 2001 White Paper (CEC, 2001a). This strategy, covering the period up to 2010 (with an update in 2006 that extended analysis to 2020), ${ }^{6}$ outlined a number of key objectives for transportation in Europe such as providing high levels of mobility to people and businesses while protecting passenger safety, energy security, sustainability and efficiency(CEC, 2006).

While longer term objectives aimed at balancing these competing needs were referred to in the 2001 White Paper, specific long-term policy outcomes were beyond its scope. Accordingly, in 2008, the Commission proposed a strategy for greening transportation. The subsequent White Paper, launched in 2011 (CEC, 2011a), attempts to set out a roadmap for a single transportation area and recognises the need for analyses of longer term transportation trends and proposed goals over a time frame of 20-40 years (CEC, 2007). Specifically, it refers to the need to reduce greenhouse gas emissions by at least $60 \%$ by 2050 with respect to 1990 levels. Without any action, it projects that $\mathrm{CO}_{2}$ emissions will be one third 
higher by that time. Consequently, while the inter-relations between transport and other areas in the economic, environmental and social spheres were alluded to, it is only with the most recent white paper that they have begun to be analysed together. For a broader overview of European policymaker's goals in regard to longer-term climate change objectives, we can continue to look towards the SDS (CEC, 2001b).

\section{The European Union Sustainable Development Strategy}

The initial move towards sustainability in policymaking was the foundation and reporting of the World Commission on Environment and Development-the 'Brundtland Commission' - in 1987 (UN, 1987). Its definition of sustainability-development meeting the needs of the present without compromising the ability of future generations to meet their own needs - is the most frequently cited one. The 1992 United Nations Conference on Environment and Development (UNCED) in Rio de Janeiro, Brazil followed. It adopted Agenda 21 (the Rio Declaration). By 2001, European leaders also moved to incorporate sustainability into the policymaking lexicon. The European Council presented A Sustainable Europe for a Better World: A European Strategy for Sustainable Development (CEC, 2001b). First proposed by the European Commission, it was adopted as the Sustainable Development Strategy (SDS) in 2001.

Initially a broad statement of intent recognising the relationship between long-term economic growth, social cohesion and environmental protection, the strategy was re-launched in 2006 and further reviewed in 2009 with specific targets updated and developed. ${ }^{7}$ The renewed strategy aims to implement a coherent long-term strategy and places emphasis both on immediate problems and also on longerterm objectives. The 2009 review focused on 'mainstreaming' sustainable development policies into European policymaking and reiterated the updated goals. The review outlines an absolute target of a $15-30 \%$ reduction over $1990 \mathrm{CO}_{2}$ emission levels by $2020 ;^{8}$ this was subsequently articulated by the Commission as a commitment to reduce emissions by $20 \%$ by 2020 in the absence of an international agreement on climate change and $30 \%$ with one (CEC, 2008). It also defines the $2^{\circ} \mathrm{C}$ cap on temperature increases over the century compared to pre-industrial levels. The European Council subsequently translated this into an EU objective of $60 \%$ to $80 \%$ reduction over 1990 levels in 2050 (CEU, 2007). The overall transportation objective is identified as ensuring that transport systems meet society's economic, social and environmental needs whilst minimising negative transport-related externalities in these areas. Transportation targets include decoupling economic growth and transport demand, reducing GHG emissions from transport, modal shift towards more efficient modes, and reducing $\mathrm{CO}_{2}$ emission from new light duty vehicles. Initially set at 120 grams of $\mathrm{CO}_{2}$ per kilometre $\left(\mathrm{gCO}_{2} / \mathrm{km}\right)$ by 2012 , the objective was redefined in 2009 (regulation No 443/2009) to be $130 \mathrm{gCO}_{2} / \mathrm{km}$. The former target was postponed to 2015 ; an additional goal of $95 \mathrm{gCO}_{2} / \mathrm{km}$ by 2020 was stated. ${ }^{9}$ 
Despite the flexibility in target formulation and development shown in the SDS process, neither it nor the various transport white papers explore how the achievement of the long-term climate change goal will impact on shorter-term transportation targets. While some targets have broad interpretations so as to be able to incorporate the impacts of the long-term targets, others are more specific. This juxtaposition between the short-term sub-targets in EU policy-making related to transportation and the longterm climate change objectives develops into an interesting story for researchers. This is especially true given that the EU proposes to embark on a process that will indirectly address these interactions more closely. The 2011 White Paper (CEC, 2011a) adopts some 40 initiatives for the next decade with the aim of building a competitive and efficient transport system while dramatically reducing Europe's dependence on imported energy and cutting transport carbon emissions 60\% below their 1990 level by 2050. But little mention is made of the shorter-term implications of meeting these longer-term targets. We investigate this relationship and, in doing so, complement the recent White Paper by developing a policy scenario aimed at exploring the impact of achieving the ultimate climate change aims of both a $20 \%$ and a $60-80 \%$ reduction in $\mathrm{CO}_{2}$ emissions by 2020 and 2050 respectively on transport sub-targets.

\section{Scenario Development}

The baseline and the policy scenario that allow us to test our research hypothesis are projections of the IMACLIM-R model; both the model and the scenario assumptions are outlined below.

\section{III.1. The IMACLIM-R Model}

IMACLIM-R is a hybrid recursive general equilibrium model of the world economy divided into 12 regions and 12 sectors (Sassi et al., 2009). The model is solved in sequential yearly time steps. The base year of the model (2001) is built on the balanced Social Accounting Matrix (SAM) of the world economy developed by the Global Trade Analysis Programme (GTAP-6 database), modified to accommodate the 2001 International Energy Agency (IEA) energy balances. This data treatment effort is done to base the IMACLIM-R model on a set of hybrid energy-economy matrixes where the production and consumption volumes of the energy sectors are expressed in genuine energy units (million tons-of-oil equivalent, MTOE).

As a general equilibrium model, IMACLIM-R provides a consistent macroeconomic framework to assess the energy-economy relationships by means of clearing factor and goods markets. Rooted in its hybrid calibration, the modelling architecture specifically aims at an easy incorporation of technological information coming from bottom-up models and experts' judgements into the projected economic trajectories: physical variables that explicitly characterise equipment, infrastructure and technologies (e.g. the 
efficiency of cars, the intensity of production in transport measured in tonne-kilometres, etc.) allow rigorously modelling how final demand and technical systems are transformed by economic incentives. The economy is thus defined both in money-metric terms and in physical quantities, with the two dimensions linked by a price vector. This dual vision is designed to guarantee a realistic technical background to the projected economy or, conversely, a realistic economic background to any projected technical system.

To fully exploit the potential of this dual representation requires abandoning the use of conventional aggregate production functions that, after Berndt and Wood (1975) and Jorgenson (1981), were admitted to mimic the set of available aggregate production techniques and thus the technical constraints impinging on an economy. Indeed, it is arguably impossible to find mathematical functions flexible enough to encompass different scenarios of structural changes resulting from the interplay between consumption styles, technologies and localisation patterns (Hourcade, 1993), for small as well as for large departures from the reference equilibrium. In IMACLIM-R, the absence of formal production functions is compensated for by a recursive structure that allows for a systematic exchange of information between:

- An annual static equilibrium module with Leontief production functions (fixed equipment stocks and intensities of intermediary inputs, especially labour and energy)-but flexible utilisation rates. Solving this equilibrium at some year $t$ provides a snapshot of the economy: information about relative prices, output levels, physical flows and profit rates for each sector and allocation of investments among sectors.

- Dynamic modules, including demography, capital dynamics and sector-specific reduced forms of technology-rich models, most of which assess the reactions of technical systems to the previous static equilibria. These reactions are then reintroduced into the static module in the form of updated input-output coefficients to calculate year $t+1$ equilibrium.

Between two equilibria, technical choices are fully flexible for new capital only: input-output coefficients and labour productivity indexes are modified at the margin, to account for the fixed techniques embodied in existing equipment and resulting from past technical choices. This general 'putty-clay' assumption is critical to representing the inertia in technical systems and the perverse effect of volatility in economic signals.

IMACLIM-R thus generates economic trajectories by solving successive yearly static equilibria of the economy interlinked through dynamic modules. Within the static equilibrium, in each region, the demand for each good is derived from household consumption, government consumption, investment and intermediate uses from the production sectors. Supply is derived from domestic production or imports, as all goods and services are traded on world markets. Domestic and international markets for all 
goods-excluding labour-are cleared by a unique set of relative prices that depend on the demand and supply behaviours of representative agents. The calculation of this equilibrium determines relative prices, wages, labour, quantities of goods and services, and value flows.

In this framework, the main exogenous drivers of economic growth are population and labour productivity dynamics. However, international trade, particularly that of energy commodities, and imperfect markets for both labour (wage curve) and capital (constrained capital flows, varying utilisation rates of productive capacities) can significantly impact on economic growth.

In the IMACLIM-R model transportation activities are typically modelled as complex technical systems constrained by the consistent general macroeconomic framework (cf. Appendix):

- First, the transportation demand described in the static equilibrium module allows for the representation of stylised facts, such as rebound effects associated with energy efficiency improvement or the demand induction by infrastructure that impact both total mobility and the underlying modal breakdown. To that end, the mobility of households is defined as an aggregate of 4 imperfectly substitutable travelling modes (air travel, public terrestrial modes, personal cars and non-motorised modes). It is one of the elements of the utility function of the representative household of each region. In addition to their budget constraint, households are subject to a travelling-time constraint. Last but not least, a 'travelling time efficiency' (average distance covered in an hour of time) factor for each mode is described as an increasing function of public investment in the infrastructure dedicated to this mode. As for productive sectors, transport consumption, an intermediate input, depends on the crossing of specific input-output coefficients (reflecting each sector's transportation intensity) and the level of activity in each economic sector.

- Second, the transportation dynamic module allows for the altering of technical constraints that hinge on transportation demand formation in the static equilibrium: the module keeps track of and marginally modifies the fleet composition and energy efficiency of personal cars, the transport intensity of economic activity and, last but not least, the particulars of infrastructure policies.

The total time dedicated by households to mobility evolves in tandem with total population. The motorisation rate is a function of per capita disposable income, according to an income-elasticity that quadratically declines as it increases, up to a 700 vehicles per 1000 inhabitants asymptote meant to translate a saturation effect.

On the technology side, ${ }^{10}$ evolution of the mean energy intensity of the automobile fleet is related to final energy prices through a representation of households' equipment choices among 5 representative car technologies: standard and efficient conventional cars, standard and efficient hybrid cars and electric cars. Each technology is characterised by a capital cost and an energy efficiency expressed in litres of gasoline equivalent (Ige) per 100 kilometres. Table 1 sums up the technology characteristics for Eu- 
rope. ${ }^{11}$ Each year, car sales induced by the evolution of the equipment rate and retirement of the oldest vintage are split between the 5 technologies according to their lifecycle costs (LCC) over an undifferentiated 15-year usage and for the current region-specific average annual mileages. The split is dictated by a multinomial logit function to account for heterogeneous preferences and the diversity of car uses, based on a $13 \%$ private discount rate. The capital costs of each technology evolve according to a $10 \%$ learning curve, ${ }^{12}$ while the energy intensities are constant over time: the efficient versions of the conventional and hybrid technologies amount to efficiency asymptotes at the projecting horizon (2050); the endogenous shifts of their rates of penetration allow covering a continuum of (average) fuel efficiencies and $\mathrm{g} / \mathrm{km}$ emissions for both technologies between the higher bounds defined by their standard versions and the lower bounds defined by their efficient versions. ${ }^{13}$

\begin{tabular}{lccccc}
\hline & $\begin{array}{c}\text { Conventional, } \\
\text { standard }\end{array}$ & $\begin{array}{c}\text { Conventional, } \\
\text { efficient }\end{array}$ & $\begin{array}{c}\text { Hybrid, } \\
\text { standard }\end{array}$ & $\begin{array}{c}\text { Hybrid, } \\
\text { efficient }\end{array}$ & $\begin{array}{c}\text { Electric } \\
\text { car }\end{array}$ \\
\hline $\begin{array}{l}2001 \text { capital cost, } \\
\text { thousand USD }\end{array}$ & 17.5 & 20 & 25 & 35 & 35 \\
$\begin{array}{l}\text { Consumption, } \\
\text { Ige per 100km }\end{array}$ & 9.0 & 6.7 & 4.5 & 2.4 & 2.0 \\
$\begin{array}{l}\text { On-road emissions, } \\
\mathrm{gCO}_{2} / \mathrm{km}\end{array}$ & 226 & 168 & 113 & 60 & 0 \\
\hline
\end{tabular}

Table 1. European car technologies parameters

Various investment policies can be tested for their impact on average modal speeds. Throughout this paper and due to brevity concerns, however, we stick to the conservative assumption that the building of transportation infrastructure follows the evolution of modal mobility.

Road and rail freight and public passenger transportation are aggregated in one productive sector. The evolution of this sector's energy input coefficients therefore accounts for both energy efficiency gains and shifts between road and rail modes. This evolution is triggered by final energy price variations, based on a compact reaction function calibrated on bottom-up information from the POLES energy sector model (Criqui, 2001). The evolution of the freight content of economic growth, which is represented by the transportation input-output coefficients of all the productive sectors in the economy, is an exogenous scenario variable in this paper. However, we note that it is indeed debatable how energy prices affect a firm's choice of localisation and production management and these parameters are likely to play a central role in cost-effective mitigation policies (Crassous et al., 2006).

Finally, fuels are produced by a petroleum products sector, undifferentiated between gasoline and diesel. Biofuels and coal-to-liquid (CTL) fuels progressively enter the fuel mix. Biofuel penetration follows a set of worldwide supply curves provided by the IEA (IEA, 2006, pp. 283 and 288) for bio-ethanol and bio-diesel production, that are transposed as functions of the production price of conventional fuels 
augmented by the carbon tax differential (the difference between the carbon tax levied on conventional fuels and that levied on each biofuel). ${ }^{14} \mathrm{CTL}$ penetration is based on a microeconomic representation of investment behaviour, taking into account the dynamics of oil prices and some constraint on growth also derived from IEA analysis (IEA, 2008). ${ }^{15}$

\section{III.2. The baseline or 'reference' (REF) scenario}

The baseline or 'reference' (REF) scenario depicts business-as-usual economic growth in the absence of any carbon constraint (Table 2). At the world level, it envisages a doubling of real per capita income between 2001 and 2050, and thus corresponds to the lower range of the SRES scenarios (Nakicenovic et al., 2000), between the A2 and the B2 markers (which multiply per capita income by 1.8 and 2.5 respectively). Behind this aggregate picture, regional dynamics differ substantially as they are characterised by a partial catch up between industrialised and developing countries (cf. e.g. Barro and Sala-i-Martin, 1991, 1992; Quah, 1996): ${ }^{16}$

- Europe and the other industrialised countries (OIC) suffer from a demographic slowdown that is unequally compensated by sustained gains of labour productivity. Compared to OIC, Europe is assumed to benefit from higher labour productivity improvements over the first three decades (the catch-up hypothesis), which results into higher growth.

- China and India have their extremely high current growth rates reduced, as ( $i$ ) their labour productivity improvements increase to a peak, (ii) their demography stabilises, and (iii) rapidly increasing energy prices hamper their relatively energy-intensive economic activity.

- Fossil fuels exporters (FFE) suffer from both stabilising demographics and a relatively low gain in labour productivity, that are imperfectly compensated by the rents they extract from increasingly tense energy markets.

- In the rest of the world (ROW), increases in labour productivity slowly take over the sheer impact of demographics as the latter effect slows down.

\begin{tabular}{lcccc}
\hline & $2001-15$ & $2016-30$ & $2030-50$ & $2001-50$ \\
\hline Europe & $2.6 \%$ & $1.9 \%$ & $0.9 \%$ & $1.7 \%$ \\
Other industrialised countries & $2.3 \%$ & $1.6 \%$ & $1.5 \%$ & $1.7 \%$ \\
China and India & $9.6 \%$ & $3.5 \%$ & $2.1 \%$ & $4.5 \%$ \\
Fossil fuels exporters & $5.9 \%$ & $2.7 \%$ & $1.3 \%$ & $2.9 \%$ \\
Rest of the world & $5.1 \%$ & $3.3 \%$ & $2.6 \%$ & $3.4 \%$ \\
\hline
\end{tabular}

Table 2. Average annual growth of real GDP, REF scenario 


\begin{tabular}{lcccc}
\hline & $2001-15$ & $2016-30$ & $2030-50$ & $2001-50$ \\
\hline Europe & $1.3 \%$ & $-0.1 \%$ & $-0.1 \%$ & $0.3 \%$ \\
Other industrialised countries & $1.4 \%$ & $0.4 \%$ & $0.4 \%$ & $0.7 \%$ \\
China and India & $6.9 \%$ & $1.5 \%$ & $1.2 \%$ & $2.8 \%$ \\
Fossil fuels exporters & $3.4 \%$ & $1.0 \%$ & $0.2 \%$ & $1.3 \%$ \\
Rest of the world & $3.8 \%$ & $2.1 \%$ & $2.3 \%$ & $2.7 \%$ \\
\hline
\end{tabular}

Table 3. Average annual growth of $\mathrm{CO}_{2}$ emissions, $\mathrm{REF}$ scenario

Turning to environmental performance, the comparison of Table 2 and Table 3 reveals a significant decoupling of growth and $\mathrm{CO}_{2}$ emissions. In the absence of carbon constraint this is mainly due to two major determinants:

- First, the physical constraints that limit the evolution of fossil fuel supply lead to a general increase of fossil energy prices along the projection. The price of coal on international markets experiences a 73\% increase between 2001 and 2050, and the price of natural gas increases by almost 160\% over the same period. The price of oil displays the most dramatic increase (cf. Figure 4 below): starting from $\$ 29$ per barrel (hereafter $/ \mathrm{bbl}$ ) in $2001,{ }^{17}$ it peaks at a $\$ 175 / \mathrm{bbl}$ maximum in 2037 , when the continuingly growing global demand comes closest to the ever slower developing global production capacity. ${ }^{18}$ After 2037 it gradually decreases, reaching $\$ 120 / \mathrm{bbl}$ in 2050 , as energy-efficient technologies enter the markets and alternative liquid fuel production (mainly second generation biofuels and synthetic fuels from coal-to-liquid production) develops. This general increase in fossil fuel prices fosters both the penetration of carbon-free energy sources (renewable and nuclear) into the primary energy mix, and the diffusion of energy-efficient equipment, which reduce the energy intensity of economic growth. Higher energy prices also induce structural changes in the econo mies in favour of the less energy-intensive activities.

- Second, the general increase in wealth is endogenously associated with a dematerialisation of growth: as per capita income increases, economies move from a base of (energy-intensive) heavy industries to one in which services dominate. Dematerialisation is projected for the industrialised world, to a lesser extent for China and India, and in a subtly different way for fossil fuels exporters as well (a significant part of their dematerialisation occurs through the increasing rents they draw from energy markets). It is much weaker for the rest of the world due to the 'mimetic development' assumption backing the REF scenario: developing countries are assumed to pursue the same lifestyle as industrialised countries as their per capita income rises: they increase the size of their homes and buy more home equipment, switch to personal cars as their dominant transportation mode, etc. - these development trends are explicitly modelled in IMACLIM-R. 
For Europe, the resulting carbon emissions profile rises to a $+19 \%$ (over its 1990 level) peak in 2020, then gradually decreases to reach $+13 \%$ in 2050 (Figure 1).

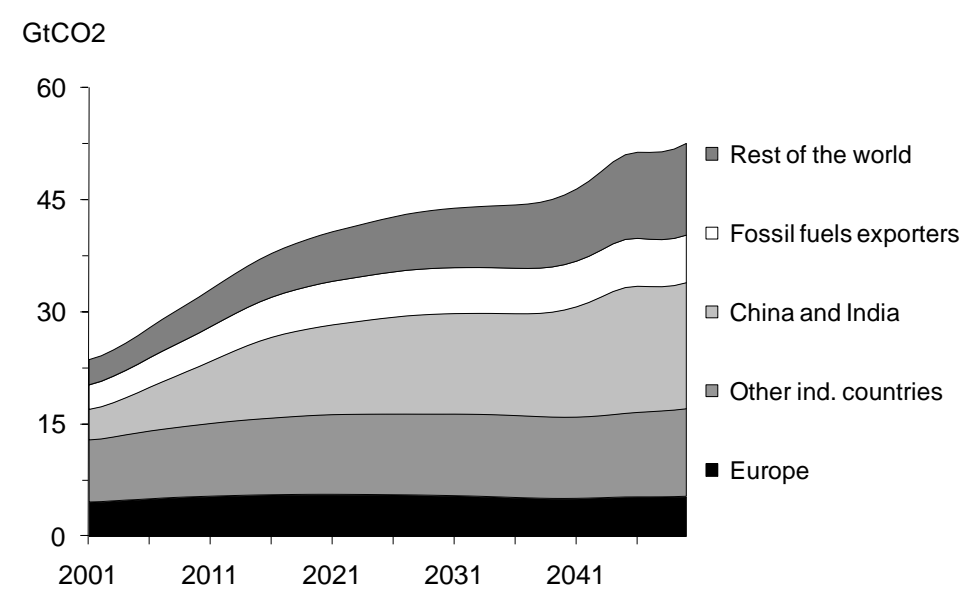

Figure 1. $\mathrm{CO}_{2}$ emissions in the REF scenario

\section{III.3. The 'overarching carbon constraint' scenario}

The 'overarching carbon constraint' (OCC) policy scenario departs from the REF scenario in that it envisages the implementation of carbon prices on a global scale from 2011 on, based on:

- The central assumption that Europe aims at $\mathrm{CO}_{2}$ emissions both at least $20 \%$ below their 1990 level in 2020, and with a long term objective at the lower range of its 60 to $80 \%$ target. Compliance with these constraints is attained through the simplest instrument of a uniform pricing of carbon (a generalised carbon tax).

- The complementary hypothesis that the world outside Europe follows the European lead by applying the European price signals downgraded by $20 \%$ for the OIC, and $80 \%$ for all other regions.

With our focus on Europe and its transportation activities, the latter set of assumptions is not essential to our demonstration. It is only proposed as a more plausible option than unilateral action by Europe, which would cause strong distortions on international markets given the levels of carbon prices implied by the constraints.

Figure 2 plots one European emission path compatible with these objectives, and the emissions of the 4 other world regions previously outlined implied by their crudely hypothesised 'follower behaviour'. ${ }^{19}$ Global emissions reach a strikingly early 32,8 billion tonnes of $\mathrm{CO}_{2}$ (hereafter $\mathrm{GtCO}_{2}$ ) peak in 2012, then decrease down to $15,9 \mathrm{GtCO} 2$ in 2050. European emissions, on which we focus, reach an even more early 2010 peak at $12 \%$ over their 1990 level; they then decrease to $22 \%$ below this level in 2020 , and end up at $65 \%$ below this level in 2050 . 


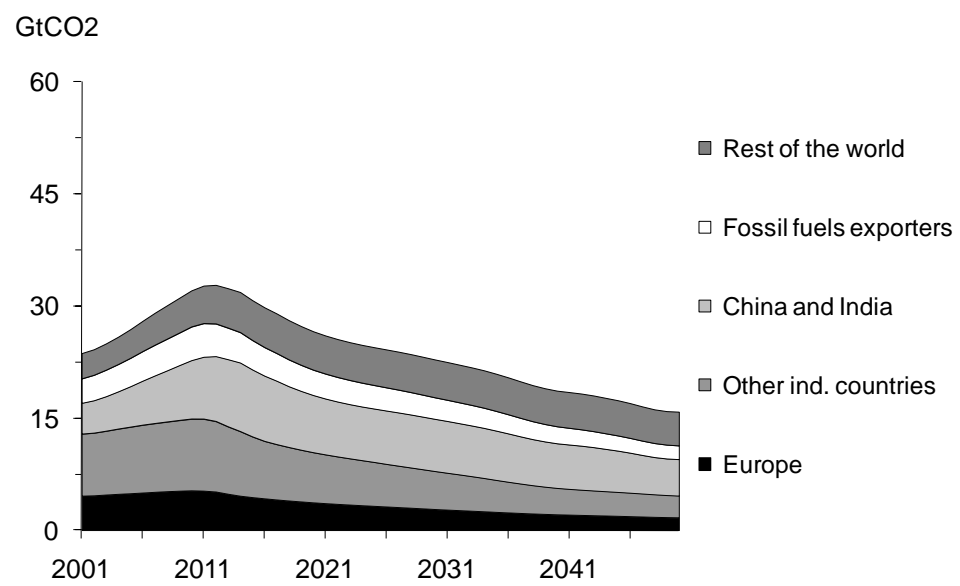

Figure 2. $\mathrm{CO}_{2}$ emissions in the OCC scenario

The price signals required to achieve the challenging European emission reduction objectives, together with their downgraded values prevailing in other regions of the world, are presented in Figure 3 . The European trajectory can be divided in three characteristic periods:

- Between 2011 and 2030 the price of carbon increases very fast (+27.2 year 2001 US dollars per tonne of $\mathrm{CO}_{2}-$ hereafter $\$ / \mathrm{tCO}_{2}-$ per year) to reach $\$ 272 / \mathrm{tCO}_{2}$ in 2020 , then fast $(+\$ 11.6 / \mathrm{tCO}$ per year) to $\$ 388 / \mathrm{tCO}_{2}$ in 2030 . The particular shape of this signal is related to a demanding 2020 reduction objective (corresponding to a $33 \%$ decrease from REF emissions) that has to circumvent the high inertia of capital stocks and the myopic behaviour of economic agents.

- Between 2030 and 2040 the price of carbon slightly decreases, as the technical change induced by early and ambitious climate policies diffuses, developing some emission reduction potentials at lower costs.

- After 2040, the looming stringent 2050 target requires additional reductions that are more expensive and carbon prices again experience a fast increase $\left(+\$ 10.3 / \mathrm{t} \mathrm{CO}_{2}\right.$ per year). 


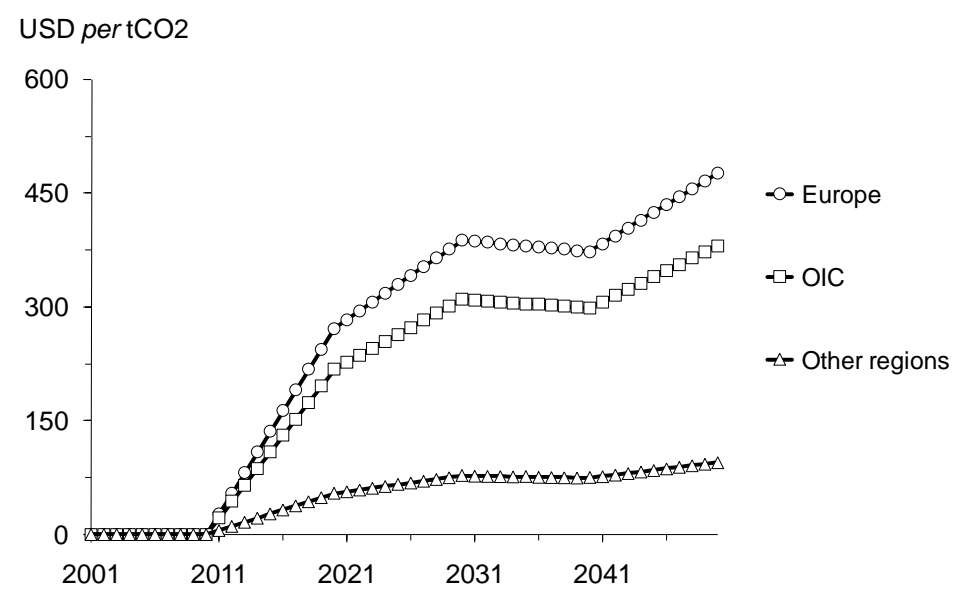

Figure 3. $\mathrm{CO}_{2}$ price trajectories in the OCC scenario ${ }^{20}$

The emission reductions triggered by those prices are related to major changes in the European energy sector. They are obtained, on the demand side, through the rapid diffusion of very-low-emission equipment in the building, transportation (see below), and industrial sectors, that allow a $59 \%$ reduction in the primary energy intensity of European GDP between 2001 and 2050-while in 2020 the reduction is already of $19 \%$ compared to 2001 . On the supply side, low-carbon and carbon-free energy technologies, such as renewables, third generation nuclear power, and carbon capture and storage spread widely to allow a $60 \%$ cut in the $\mathrm{CO}_{2}$ intensity of total primary energy supply between 2001 and 2050-the cut is $35 \%$ in 2020 compared to 2001.

\begin{tabular}{|c|c|c|c|c|}
\hline & $2001-15$ & $2016-30$ & $2030-50$ & $2001-50$ \\
\hline Europe & $\begin{array}{l}2.4 \% \\
(-0.2)\end{array}$ & $\begin{array}{l}1.8 \% \\
(-0.1)\end{array}$ & $\begin{array}{l}1.1 \% \\
(+0.1)\end{array}$ & $\begin{array}{l}1.6 \% \\
(-0.0)\end{array}$ \\
\hline Other industrialised countries & $\begin{array}{l}2.1 \% \\
(-0.2)\end{array}$ & $\begin{array}{l}1.5 \% \\
(-0.0)\end{array}$ & $\begin{array}{l}1.6 \% \\
(+0.1)\end{array}$ & $\begin{array}{l}1.7 \% \\
(-0.0)\end{array}$ \\
\hline China and India & $\begin{array}{l}9.1 \% \\
(-0.4)\end{array}$ & $\begin{array}{l}3.3 \% \\
(-0.1)\end{array}$ & $\begin{array}{l}2.3 \% \\
(+0.1)\end{array}$ & $\begin{array}{l}4.4 \% \\
(-0.1)\end{array}$ \\
\hline Fossil fuels exporters & $\begin{array}{l}4.8 \% \\
(-1.0)\end{array}$ & $\begin{array}{l}2.6 \% \\
(-0.1)\end{array}$ & $\begin{array}{l}1.7 \% \\
(+0.4)\end{array}$ & $\begin{array}{l}2.8 \% \\
(-0.1)\end{array}$ \\
\hline Rest of the world & $\begin{array}{l}4.9 \% \\
(-0.1)\end{array}$ & $\begin{array}{l}3.3 \% \\
(-0.0)\end{array}$ & $\begin{array}{l}2.6 \% \\
(-0.0)\end{array}$ & $\begin{array}{l}3.4 \% \\
(-0.1)\end{array}$ \\
\hline
\end{tabular}

Table 4. Average annual growth of real GDP, OCC scenario

In brackets: percentage point deviation from the REF scenario ( $c f$. Table 2).

The general macroeconomic consequences of such major mutations of the energy systems are not as dramatic as one might expect-although it must be kept in mind that a GDP growing $1.7 \%$ a year will be $5 \%$ above one growing $1.6 \%$ a year after 50 years. They depend to some extent on the characteristics of each region, but, generally speaking, economies bear the brunt of the constraint in the shorter run (Table 4Erreur! Source du renvoi introuvable.Erreur! Source du renvoi introuvable.), when they are 
hampered by the inertia of their energy systems; in the longer run, when the necessary adjustments have taken place, growth tends back towards its REF levels, and even overshoots it in some regions. The possibility of overshooting the baseline in such a modelling architecture as IMACLIM-R is linked to the imperfect foresight assumption it adopts for all economic agents. The REF scenario is characterised by huge tensions on the oil markets that are not well anticipated. The climate policy gives a strong signal towards decarbonisation early enough in the trajectory to induce additional technical change for energy efficient technologies that does not occur in the baseline because of the lack of an early enough anticipation of the future tensions on oil markets. Economies thus can use more efficient technologies in the OCC scenario for a cost lower than in the REF scenario. It is indeed the case for Europe, which, after a loss of 0.2 points of annual growth between 2001 and 2015, decreasing to 0.1 point between 2016 and 2030 , experiences a gain of 0.2 points of annual growth in the 20 last years of projection.

The impact on the other industrialised countries is smaller because of both a lower carbon price, and larger low-cost reduction potentials (esp. in the US). India and China are particularly hit, as they combine the impacts of a carbon constraint-much downgraded but still significant for their developing carbon-intensive economies - with that of a diminution of international trade mechanically caused by a lower global growth. In a similar way but on different markets, fossil fuel exporters are strongly hit before 2030, as they see both their export volumes greatly reduced, and the consequently much lower tensions on the oil and gas markets decrease their rents ( $c f$. the OCC vs. REF price of oil on international markets, Figure 4 below).

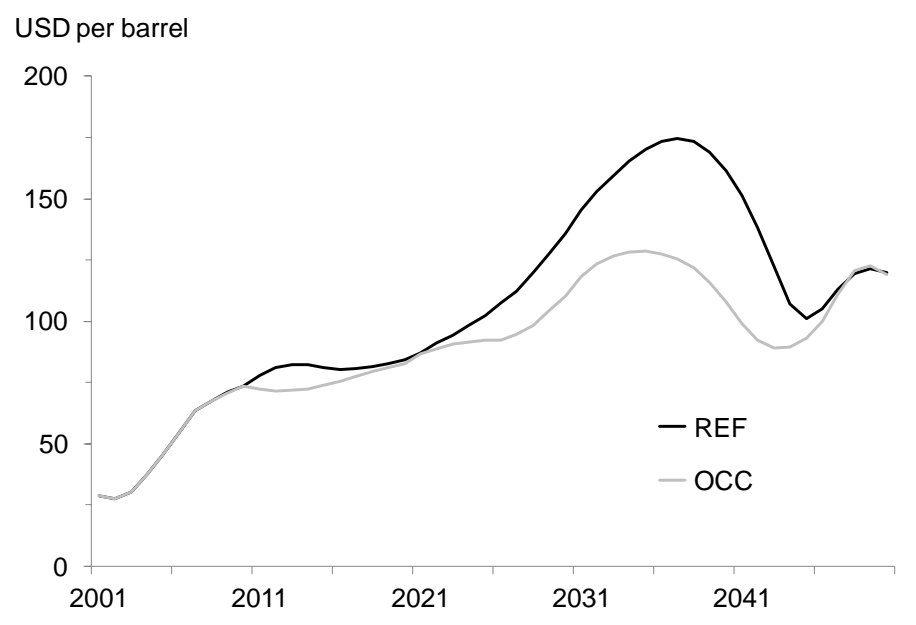

Figure 4. International price of oil in the REF and OCC scenarios ${ }^{21}$

Still, the OCC scenario as it stands is somewhat conservative as it does not hypothesise climate policyinduced changes in lifestyles, location and urbanisation choices. It would be reasonable to assume that climate policies could be complemented by other public policies to induce such behavioural changes 
(that are not very reactive to carbon prices) in a consistent way with the climate objective. The cost of stabilisation would probably be reduced with such a policy package (cf. e.g. Gusdorf et al., 2008).

\section{European road transportation: from current trends to a carbon constrained European Union}

Let us now turn to the analysis of how the 2020 and 2050 OCCs impact the $\mathrm{CO}_{2}$ emissions from ground transportation in Europe. To systematise this analysis we will successively report mobility, energy consumption (backed by an analysis of the private car fleet), and $\mathrm{CO}_{2}$ emissions for motorised ground transport.

Aggregate motorised ground passenger mobility (i.e. the sum of private car, bus and rail passenger mobility), measured in passenger-kilometres ( $\mathrm{pkm})$, appears quite resistant to the high carbon prices prevailing in the OCC scenario (Figure 5, left-hand axis). Its impact is reminiscent of the GDP trends: a slight decrease is observed in the short- to medium-term, then some catching-up occurs beyond 2030, although pkm stay below their REF value. Within this aggregate evolution the split between public and private transportation is also relatively unchanged. It only slightly evolves in the favour of the former modes, which end up above their REF level by 2050 as they naturally benefit from a much lower carbon intensity per pkm. Notwithstanding, these results fundamentally confirm the oft-reported finding (see e.g. Espey, 1998, or Goodwin et al., 2004, for a survey), somewhat disturbing for policy-makers, that even high carbon prices have only a marginal impact on mobility in both quantitative and qualitative terms.

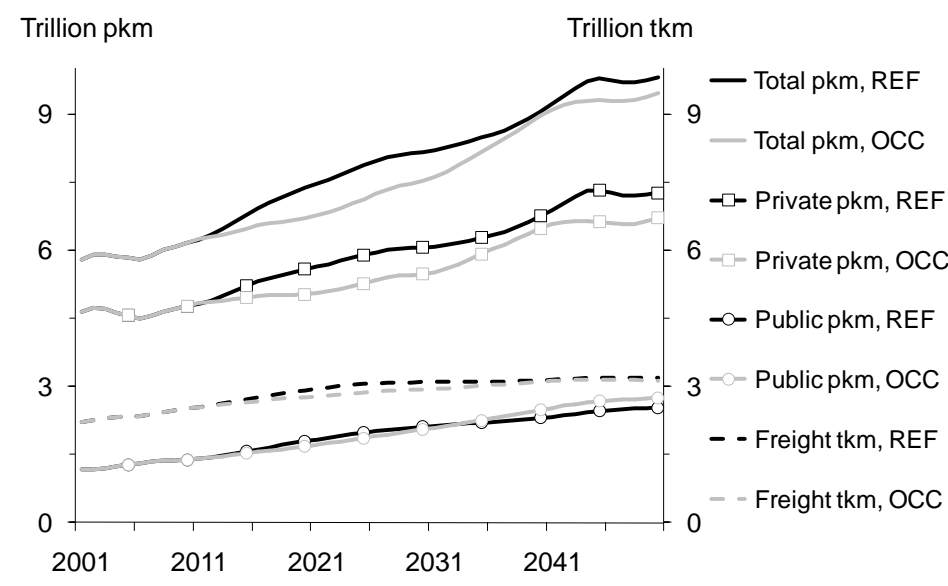

Figure 5. European motorised ground mobility

The evolution of freight tonnes-kilometres $(\mathrm{tkm})$ follows a pattern similar to that of GDP, as freight transport highly depends on the overall level of activity. However, the impact of OCC on freight activity 
ends up being stronger $(-2.0 \% \mathrm{tkm}$ in 2050 compared to REF) than its impact on GDP (-1.1\%). This reflects the impact of the stringent climate policy on the structure of the economy, which turns towards sectors that are less intensive in materials and transportation.

Still, ground motorised mobility appears to be relatively insensitive to high carbon prices in both its passenger and freight dimensions. This result is echoed to some extent in the related energy consumption. Measured in million tonnes of oil equivalent (MTOE), consumption declines in the OCC scenario compared with their REF values (Figure 6), but the high carbon prices required by the OCC fail to curb down total energy consumption in absolute terms, and barely achieve its stabilisation. The split between fuels is also only marginally impacted; conventional fuels retain their two-third share of total energy: high carbon prices have the counter-intuitive effect of relaxing the tensions on international oil market, thus moderating the ultimate relative impact of OCC on gasoline prices. In the remaining third, however, the massive development of coal-to-liquid technologies projected in REF is blocked by high carbon prices, in the favour of biofuels, whose 2050 production is $120 \%$ higher than in the REF scenario. Although hybrid and electric cars begin to weigh in the total fleet at the end of the projected period (17.3\% market share in 2050), ${ }^{22}$ the share of electricity remains low (6.5\% in 2050) as this technology benefits from a high energy efficiency. 

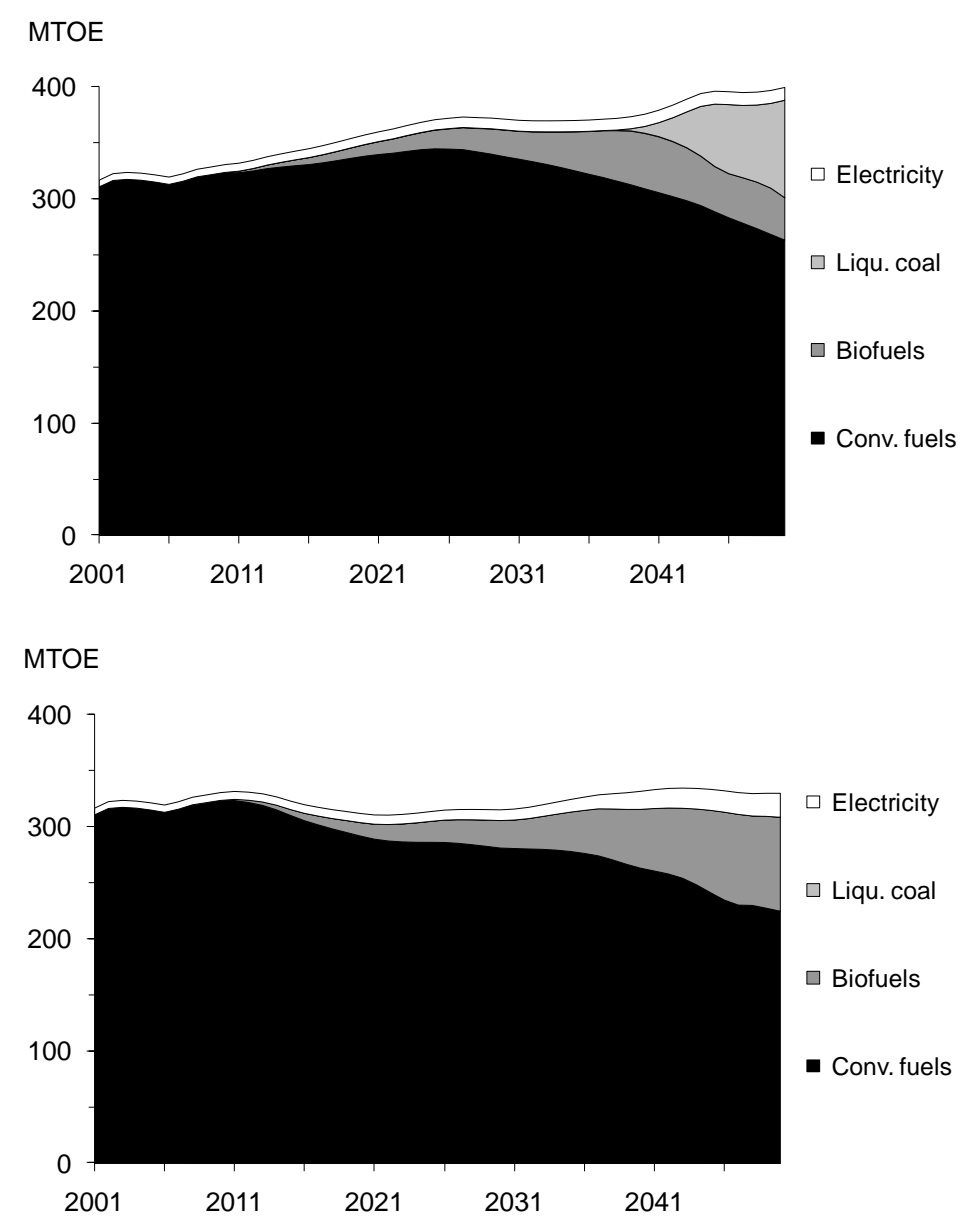

\section{Figure 6. End-use energy consumption of ground transportation, REF (upper graph) vs OCC (lower graph) scenario}

To investigate these trends further, we focus on technical changes that alter the energy intensity and fuel mix in the transportation sector.

As far as private cars are concerned, the 2001-2050 reduction in energy intensity (MTOE/pkm) shifts from $20 \%$ in the REF scenario to $34 \%$ in its OCC counterpart. These higher energy efficiency improvements are due to market penetration of more efficient conventional cars and hybrid and electric cars (Figure 7). In the OCC scenario high carbon prices act as a signal and the fleet shares of less emitting technologies are boosted. Indeed, the share of non-conventional vehicles in 2030 increases from $10 \%$ in the REF scenario to $25 \%$ in the OCC scenario. We see further sustained growth in these technologies up to 2050 where they account for $17 \%$ of the on-road fleet in the REF scenario and $44 \%$ in the OCC scenario. 

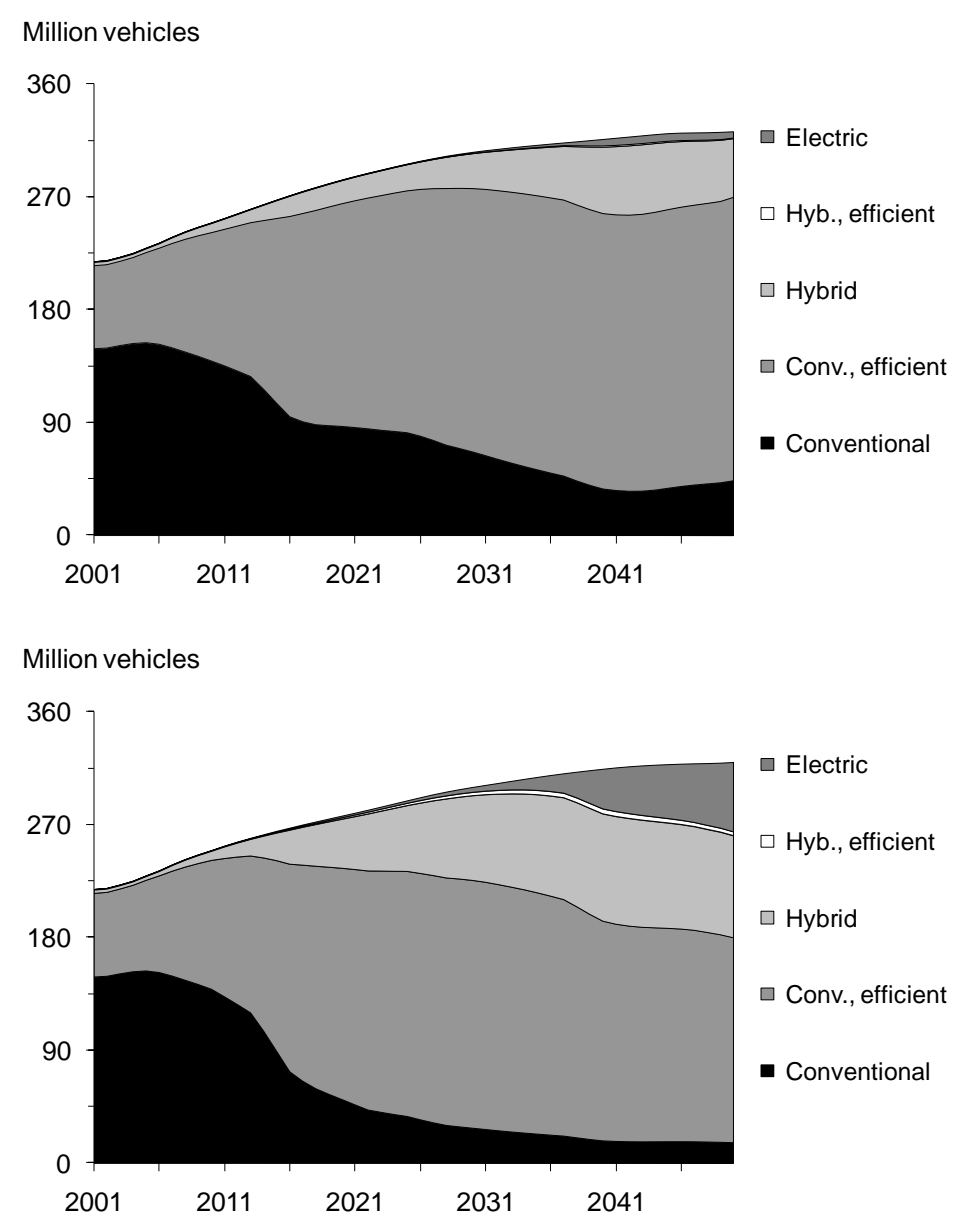

\section{Figure 7. Share of technologies in the private car fleet, REF (upper graph) vs OCC (lower graph) scenario}

While overall mobility is not affected by the carbon pricing strategy, the composition of the fleet (in terms of fuel choice and efficiency) thus undergoes some significant changes. Interestingly, we do see some catch-up in the REF scenario towards the second half of the time period. This trend occurs because of the increase in oil prices in the 2025-2040 period, which creates its own price signal to consumers. However, the massive carbon pricing in the OCC scenario induces a stronger shift towards the cleaner technologies (whereas the increases in oil prices are much more moderate due to much lower tensions on oil markets) and prevents a comeback of less efficient technologies that occurs in the REF scenario as tensions on oil market are relaxed by the increasing production of synthetic fuels.

Efficiency improvements are less important in the public transportation sector (freight and passengers) where the high carbon prices of OCC induce a modest $6.9 \%$ decrease in energy intensity compared to REF in 2050. This difference is mainly due to potentials for efficiency improvement, that are pictured by IMACLIM-R as high in the current automobile fleet (downsizing, material substitution, engine improvements), but more conservatively for trucks and buses, reflecting consensual vs. more debated assumptions (IEA, 2009). 
Turning to $\mathrm{CO}_{2}$ emissions, we find that ground transportation emissions do not follow the total emissions trend constrained by the OCC scenario, at least under our hypothesis that this trend is achieved through the sole policy instrument of uniform carbon pricing. Reductions in ground transportation emissions under OCC indeed amount to 14\% of REF emissions in 2020, 25\% in 2050 (Figure 8). These figures are to be compared with the massive overall decreases of $34 \%$ and $69 \%$ achieved at those target dates, and ultimately tend to prove that transportation stands as an obstacle to stringent stabilisation objectives, at least when these objectives are pursued through carbon pricing policies only.
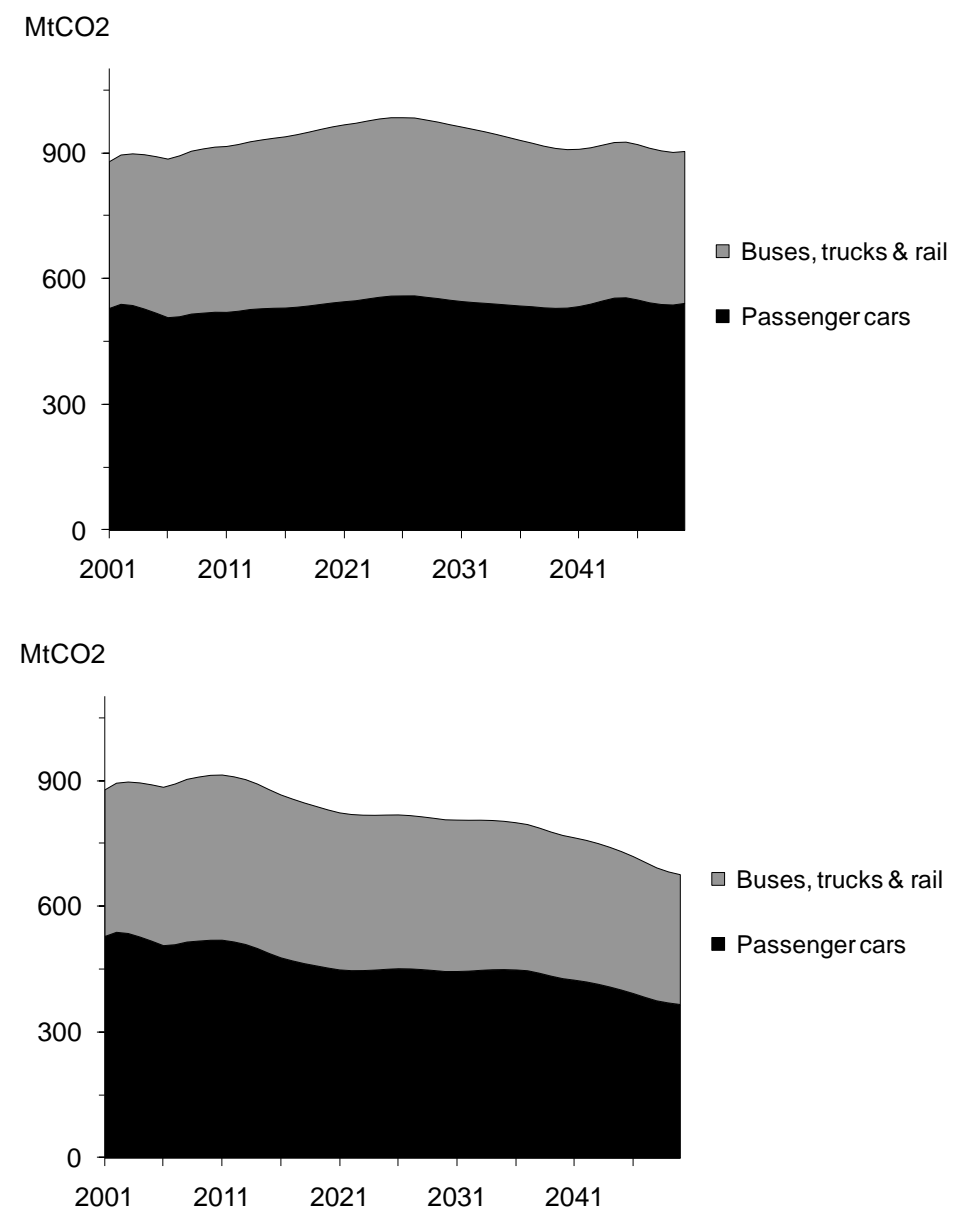

Figure 8. Tank-to-wheel $\mathrm{CO}_{2}$ emissions of ground transportation, REF (upper graph) vs OCC (lower graph) scenario

Finally, we analyse how these results translate in terms of the specific transportation targets set by the EU. The level of detail of IMACLIM-R allows us to test in particular two policy areas of the transport arena that are addressed in the SDS. The first policy area relates to the penetration of biofuels in the market for transport fuel, with targets set for 2010 and $2020 . .^{23}$ The second relates to average emissions of $\mathrm{CO}_{2}$ per $\mathrm{km}$ from the new car fleet, for 2012, 2015 and $2020 .{ }^{24}$ 
Generally speaking, we find that all the outlined targets are missed in OCC as in REF, and missed by considerable distances (Table 5).

\begin{tabular}{|c|c|c|c|c|}
\hline Target & Year & Objective & REF scenario & OCC scenario \\
\hline $\begin{array}{l}\text { Share of biofuels } \\
\text { (EC 30/2003) }\end{array}$ & 2010 & $5.75 \%$ & $0.19 \%$ & $0.19 \%$ \\
\hline $\begin{array}{l}\text { Share of biofuels } \\
\text { (CEU, 2007) }\end{array}$ & 2020 & $10 \%$ & $2.95 \%$ & $4.02 \%$ \\
\hline $\begin{array}{l}\mathrm{LDV} \mathrm{CO}_{2} \text { emis- } \\
\text { sions, bench-test } \\
\text { vintage average } \\
\text { (SDS target) }\end{array}$ & 2012 & 120 g/km & $134 \mathrm{~g} / \mathrm{km}$ & $127 \mathrm{~g} / \mathrm{km}$ \\
\hline $\begin{array}{l}\text { LDV } \mathrm{CO}_{2} \text { emis- } \\
\text { sions, bench-test } \\
\text { vintage average } \\
\text { (EC 443/2009) }\end{array}$ & 2015 & $120 \mathrm{~g} / \mathrm{km}^{\mathrm{a}}$ & $134 \mathrm{~g} / \mathrm{km}$ & $127 \mathrm{~g} / \mathrm{km}$ \\
\hline $\begin{array}{l}\text { LDV } \mathrm{CO}_{2} \text { emis- } \\
\text { sions, bench-test } \\
\text { vintage average }\end{array}$ & 2020 & $95 \mathrm{~g} / \mathrm{km}$ & $132 \mathrm{~g} / \mathrm{km}$ & $120 \mathrm{~g} / \mathrm{km}$ \\
\hline
\end{tabular}

\section{Table 5. Status of transport objectives under the two scenarios}

Bench-test vintage averages of the REF and OCC scenarios are systematically estimated $18 \%$ below the projected on-road vintage averages ( $c f$. endnote 13)

On biofuel penetration, in 2010 biofuel development spectacularly fails to meet its target, irrespective of the OCC, for the simple reason that the policy scenario does not diverge from the REF trajectory before 2011. in 2020 the OCC scenario starts to make a visible difference, as both the price incentive has developed, and time has elapsed allowing the development of production capacities. Still, the target is far from being reached: biofuels development still only makes up $40 \%$ of the target.

The results on the average $\mathrm{CO}_{2}$ efficiency of new cars are more sensitive to the OCC scenario in the short term: as early as 2012 imposing the OCC cuts the $14 \mathrm{~g} / \mathrm{km}$ compliance gap of REF in half. This higher responsiveness of fuel efficiency to pricing strategies is in part explained by the lesser inertia of mere market share shifts for already existing technologies (more efficient conventional vehicles and hybrid vehicles), compared to the development of industrial biofuel capacities. Still, by 2020 the 37 $\mathrm{g} / \mathrm{km}$ excess is only cut down to $25 \mathrm{~g} / \mathrm{km}$, and the $95 \mathrm{~g} / \mathrm{km}$ is missed by $26 \%$.

These findings point once again at the low reactivity of the transportation sector to carbon policies that are exclusively price-based. Even in an ambitious climate scenario, in which policymakers resort to a stringent pricing of carbon with the aim of fulfilling an overarching reduction objective, there is no guarantee that interim or long term policy targets will be attained for the transportation sector. The biofuel and energy efficiency policy objectives are goals in themselves, which appear to require addi- 
tional policy initiatives to be achieved. As a result, based on this evidence, we reject the hypothesis that the presence of such a long-range target will 'dominate' specific sectoral objectives.

\section{Conclusion}

Our research rejects the hypothesis that even stringent short- and long-term overarching $\mathrm{CO}_{2}$ mitigation targets dominate (i.e. necessary imply compliance with) short-run objectives in the transportation arena. More specifically, our simulations demonstrate that hitting mitigation targets in the lower range of outlined overarching European objectives, i.e. constraining $\mathrm{CO}_{2}$ emissions $22 \%$ and $65 \%$ below their 1990 level in 2020 and 2050 respectively, through the implementation of uniform economy-wide carbon prices, does not succeed in triggering significant changes in the transportation sector compatible with outlined 2010 to 2020 biofuels penetration and $\mathrm{CO}_{2}$ intensity targets. Even in the longer term, carbon prices close to an impressive $\$ 500 / \mathrm{tCO}_{2}$ do not succeed in curbing $\mathrm{CO}_{2}$ emissions from ground transportation by more than a modest $25 \%$ decrease from their baseline trend. This is a significant step away from the $60 \%$ below 1990 levels objective of the 2011 White Paper on Transport.

In policymaking terms it is tempting to jump to the conclusion that specific targets on transportation activities are superfluous, if anything unduly costly, as they suppose marginal prices higher than those triggering compliance to the overarching objectives. This would indeed echo the theoretical recommendation that an overarching constraint as carbon mitigation should not be fragmented in sectoral targets or technology choices (biofuels) following some unavoidably flawed political process, but should rather be enforced by adjusting a uniform price signal that would 'naturally' select the cheaper abatement opportunities, free of preconceptions.

For at least two reasons this recommendation can be questioned in the case of carbon mitigation. First, it only prevails in first best economic conditions (perfect markets, perfect information, perfect anticipations), whereas addressing the market failures and imperfections of real economies may require extended policy packages. Guivarch and Hallegatte (2011) thus demonstrate that complementing uniform carbon pricing with policies targeting the development of infrastructures, which is otherwise barred by imperfect foresight and split incentives, significantly cuts down the costs of the more ambitious mitigation objectives. Similarly, the carbon-efficiency mandates questioned in our research might be a relevant policy option to circumvent the 'split incentive' issues surrounding company cars. They could also be warranted to bridge the gap between the higher private discount rate governing car technology choices ( $13 \%$ in our modelling exercise) and the lower $3 \%$ to $5 \%$ discount rate commonly thought to apply to an aggregate 'social welfare' perspective. Second, even if it were possible to prove that it is economically inefficient to pursue specific transportation objectives up to 2050, it would not mean that there is no ground to do so for objectives beyond the OCC, both more stringent and more distant in 
time: the resilience of $\mathrm{CO}_{2}$ emissions from ground transportation to carbon pricing hints at a lock-in of this activity in carbon intensive trajectories, that might compromise the ability of Europe to aim at targets in the higher range of their 2050 reduction objective, or even beyond, would e.g. some updated alarming information about climate sensitivity warrant it-Vogt-Schilb and al. (2012) demonstrate indeed how technical inertia can vouch for differentiated carbon prices. This in turn highlights the urgent need for some ambitious transport-specific policy design research agenda.

\section{References}

Barro, R. J., Sala-i-Martin, X., 1991. Convergence across states and regions. Brookings Papers of Economic Activity, 22 (1), 107-182.

Barro, R. J., Sala-i-Martin, X., 1992. Convergence. Journal of Political Economy, 100 (21), 223-51.

Berndt, E., Wood, D., 1975. Technology, prices and the derived demand for energy. Review of Economics and Statistics, $57(3), 259-68$.

Bieber, A., Massot, M.-H., Orfeuil, J.-P., 1994. Prospects for daily urban mobility. Transport Reviews, 14 (4), 321-339.

Commission of the European Communities (CEC), 1992. The future development of the common transport policy. A global approach to the construction of a community framework for sustainable mobility. Transport White Paper. COM (92) 494 final, 2 December 1992, Bulletin of the European Communities, Supplement 3/93.

Commission of the European Communities (CEC), 1993. Growth, competitiveness, employment: The challenges and ways forward into the $21^{\text {st }}$ century. White Paper. COM (93) 700 final/A and B, 5 December 1993. Bulletin of the European Communities, Supplement 6/93.

Commission of the European Communities (CEC), 2001a. European transport policy for 2010: Time to decide. Transport White Paper. COM (2001) 370 final, 12 September 2001.

Commission of the European Communities (CEC), 2001b. A sustainable Europe for a better world: A European Union strategy for sustainable development. COM (2001) 264 final, 15 May 2001.

Commission of the European Communities (CEC), 2002. Towards a global partnership for sustainable development. COM (2002) 82 final, 13 February 2002.

Commission of the European Communities (CEC), 2006. Keep Europe moving. Sustainable mobility for our continent. Mid-term review of the European Commission's 2001 Transport White Paper. COM (2006) 314 final, 22 June 2006. 
Commission of the European Communities (CEC), 2007. Results of the Review of the Community Strategy to Reduce $\mathrm{CO}_{2}$ Emissions from Passenger Cars and Light-Commercial Vehicles, $\mathrm{COM(2007)} 19$ final, 7 February 2007:

http://eur-lex.europa.eu/LexUriServ/site/en/com/2007/com2007 0019en01.pdf

Commission of the European Communities (CEC), 2008. 2020 by 2020 - Europe's Climate Change Opportunity, $\operatorname{COM(2008)} 30$ final, 23 January 2008:

http://www.energy.eu/directives/com2008 0030en01.pdf

Commission of the European Communities (CEC), 2011a. Roadmap to a single European transport area.

Towards a competitive and resource efficient transport system. COM (2011) 144 final, 28 March 2011:

http://ec.europa.eu/transport/strategies/2011 white paper en.htm

Commission of the European Communities (CEC), 2011b. Energy roadmap 2050, COM(2011) 885 final, 15 December 2011:

http://eur-lex.europa.eu/LexUriServ/LexUriServ.do?uri=COM:2011:0885:FIN:EN:PDF

Commission of the European Communities (CEC), 2011c. Impact assessment. Accompanying document to the White Paper Roadmap to a single European transport area. Towards a competitive and resource efficient transport system. SEC (2011) 358 final, 28 March 2011: $\underline{\text { http://eur- }}$ lex.europa.eu/LexUriServ/LexUriServ.do?uri=SEC:2011:0358:FIN:EN:PDF

Council of the European Union (CEU), 2006. Review of the EU sustainable development strategy (EU SDS). Renewed strategy. Council of the European Union, Brussels, 26 th June 2006. http://register.consilium.europa.eu/pdf/en/06/st10/st10917.en06.pdf (accessed January, $8^{\text {th }}, 2012$ ).

Council of the European Union (CEU), 2007. Brussels European Council 8/9 March 2007, presidency conclusions. 7224/1/07 Rev 1, 2 May 2007,

http://www.consilium.europa.eu/ueDocs/cms_Data/docs/pressData/en/ec/93135.pdf (accessed Janu$\left.\operatorname{ary} 12^{\text {th }}, 2012\right)$.

Clarke, L., Edmonds, J., Krey, V., Richels, R., Rose, S., Tavoni, M., 2009. International climate policy architectures: Overview of the EMF 22 international scenarios. Energy Economics, 31, supplement 2, S64S81.

Crassous, R., Hourcade, J.-C., Sassi, O., 2006. Endogenous structural change and climate targets. Modeling experiments with IMACLIM-R. The Energy Journal, special issue Endogenous technological change and the economics of the atmospheric stabilization, 259-276. 
Criqui, P. (2001), POLES: Prospective Outlook on Long-term Energy Systems, Institut d'économie et de politique de l'énergie, Grenoble, France,

http://www.upmf-grenoble.fr/iepe/textes/POLES8p_01.pdf (accessed January 12 ${ }^{\text {th }}, 2012$ ).

Dargay, J., Gately, D., Sommer, M., 2007. Vehicle ownership and income growth, worldwide: 1960-2030. The Energy Journal, 28, 143-170.

Directorate-General for Energy (DGE), 2011. Energy roadmap 2050 - State of play: Background paper. 3 May 2011,

http://ec.europa.eu/energy/strategies/2011/doc/roadmap 2050/20110503 energy roadmap 2050 st ate of play.pdf (accessed January 12th, 2012).

Espey, M., 1998. Gasoline demand revisited: An international meta-analysis of elasticities. Energy Economics, 20 (3), 273-95.

European Environment Agency, 2012. Energy Efficiency and Energy Consumption in the Transport Sector (ENER 023). Assessment published April 2012.

http://www.eea.europa.eu/data-and-maps/indicators/energy-efficiency-and-energy-consumption-

4/assessment (accessed July 12 ${ }^{\text {th }}, 2012$ ).

Goodwin, P., Dargay, J., Hanly, M., 2004. Elasticities of road traffic and fuel consumption with respect to price and income: A review. Transport Reviews, 24 (3), 275-92.

Guivarch, C., Hallegatte, S., 2011. Existing infrastructure and the $2^{\circ} \mathrm{C}$ target. A letter. Climatic Change, $109(3-4), 801-05$.

Gusdorf, F., Hallegatte, S., Lahellec, A., 2008. Time and space matter: How urban transitions create inequality. Global Environmental Change, 18 (4), 708-19.

Hourcade, J.-C., 1993. Modelling long-run scenarios. Methodology lessons from a prospective study on a low $\mathrm{CO}_{2}$ intensive country. Energy Policy, 21 (3), 309-26.

International Energy Agency (IEA), 2004. Biofuels for transport: An international perspective. OECD/International Energy Agency, Paris, France.

International Energy Agency (IEA), 2006. Energy technology perspectives 2006. OECD/International Energy Agency, Paris, France.

International Energy Agency (IEA), 2008. World Energy Outlook. OECD/International Energy Agency, Paris, France.

International Energy Agency (IEA), 2009. Technology roadmap. Electric and plug-in hybrid electric vehicles. OECD/International Energy Agency, Paris, France.

https://www.iea.org/Papers/2009/EV PHEV Roadmap.pdf. (accessed December 13 ${ }^{\text {th }}, 2011$ ). 
Jorgenson, D.W., 1981. Energy prices and productivity growth. Scandinavian Journal of Economics, $83(2), 165-79$

Nakicenovic, N., Alcamo, J., Davis, G., De Vries, B., Fenhann, J., Gaffin, S., Gregory, K., Grübler, A., Jung, T.Y., Kram, T., La Rovere, E.L., Michaelis, L., Mori, S., Morita, T., Pepper, W., Pitcher, H., Price, L., Riahi, K., Roehrl, A., Rogner, H.-H., Sankovski, A., Schlesinger, M., Shukla, P.R., Smith, S., Swart, R., van Rooijen, S., Victor, N., Dadi, Z., 2000. IPCC special report on emissions scenarios. Cambridge University Press, Cambridge, United Kingdom and New York, NY, USA.

Quah, D., 1996. Empirics for economic growth and convergence. European Economic Review, 40 (6), 1353-75.

Rozenberg, J., Hallegatte, S., Vogt-Schilb, A., Sassi, O., Guivarch, C., Waisman, H., Hourcade, J.-C., 2010. Climate policies as a hedge against the uncertainty on future oil supply. Climatic Change, Electronic Supplementary Material.

http://www.springerlink.com/content/u45p6385t6xj8711/105842010 Article 9868 ESM.html (accessed January $12^{\text {th }}, 2012$ ).

Sassi, O., Crassous, R., Hourcade, J.-C., Gitz, V., Waisman, H., Guivarch, C., 2009. IMACLIM-R: A modelling framework to simulate sustainable development pathways. International Journal of Global Environmental Issues, 10 (1-2), 5-24:

http://www.imaclim.centre-

cired.fr/IMG/pdf/Sassi et al 2010 ImaclimR a modelling framework to simulate sustainable devel opment pathways.pdf

Schäfer, A., Victor, D., 2000. The future mobility of the world population. Transportation Research Part A: Policy and Practice, 34(3), 171-205.

Sterner, T. (2003) Policy instruments for environmental and natural resource management. Resources for the Future, Washington, D.C.

United Nations (UN), 1987. Report of the world commission on environment and development. United Nations General Assembly Resolution 42/187, 11 December 1987.

Vilhelmson, B., 1999. Daily mobility and the use of time for different activities: The case of Sweden. GeoJournal, 48 (3), 177-185.

Vogt-Schilb, A., Meunier, G., Hallegatte, S., 2012. How inertia and limited potentials affect the timing of sectoral abatements in optimal climate policy. Policy Research Working Paper 6154, The World Bank, Sustainable Development Network, Office of the Chief Economist. 
Vogt-Schilb, A., Sassi, O., Cassen, C., Hourcade, J.-C., 2009. Electric vehicles: What economic viability and climate benefits in contrasting futures? CIRED Working Paper,

http://www.centre-cired.fr/IMG/pdf/electricvehicule.pdf

Waisman, H., Rozenberg, J., Sassi, O., Hourcade, J.-C., 2012. Peak oil profiles through the lens of a general equilibrium assessment. Energy Policy, 48 (3), 744-753.

Zahavi, Y., Talvitie, A., 1980. Regularities in travel time and money expenditures. Transportation Research Record, 750, 13-19. 


\section{Appendix \\ Transport specifications in IMACLIM-R}

This appendix details the transport specifications of the version of IMACLIM-R implemented during the FP7 European project TranSust.Scan, in 2009. More recent versions introduce further developments.

\section{Passenger mobility demand}

At each simulation year and in each of the 12 regions modelled (for convenience we drop time and region subscripts in the following equations), households derive utility as a Stone-Geary function of consumption $C_{i}$ of $n$ goods above basic-need levels $\overline{C_{i}}$, and a mobility service $S_{m}$ :

$$
U=\prod_{i=1}^{n}\left(C_{i}-\overline{C_{i}}\right)^{\eta_{i}} S_{m}^{\eta_{m}}
$$

The elasticities of utility to the consumptions and mobility service, $\eta_{i}$ and $\eta_{m}$, are calibrated on 2001 household budget data $\left(\eta_{m}=0.129\right)$. $S_{m}$ is a Constant Elasticity of Substitution (CES) composite of $D_{i}-\overline{D_{i}}$ the pkm travelled in the 4 represented modal aggregates, air transport, private car, public transport (except air) and non-motorised modes, above basic needs $\overline{D_{i}}$ :

$$
S_{m}=\left(\sum_{i=1}^{4}\left(\frac{D_{i}-\overline{D_{i}}}{b_{i}}\right)^{\rho}\right)^{\frac{1}{\rho}}
$$

$\sigma=1 /(1-\rho)$, the elasticity of substitution between the pkm in the different modes beyond their basic needs, is set at $3.33(\rho=0.7)$ for all periods and regions. The $b_{i}$ parameters are equal to 4 for all periods and regions - this assumption amounts to fixing a unit of measurement to $S_{m}$ and does not impact on modelling results. For lack of better hypotheses, in the REF and OCC runs reported in this paper the basic needs are nil for all modes except the private car, for which they are set at $70 \%$ of the observed $2001 \mathrm{pkm}$, then progress each year at a rate $30 \%$ that of the pkm progression.

Households maximise utility under 2 constraints. They are subject to the standard budget constraint:

$$
R=\sum_{i=1}^{n} p_{i} C_{i}+p_{\text {air }} D_{\text {air }}+p_{\text {public }} D_{\text {public }}+\left(\alpha_{\text {fuel }}^{\text {car }} p_{\text {fuel }}+\alpha_{\text {elec }}^{\text {car }} p_{\text {elec }}\right) D_{\text {car }}
$$

with $R$ the consumption budget; $p_{i}$ the consumer price of good $i$; $p_{\text {air }}$ and $p_{\text {public }}$ the consumer prices of one $\mathrm{pkm}$ of those modes (reflecting the cost structure of their productions); $p_{\text {fuel }}$ and $p_{\text {elec }}$ the consumer prices of one ton-of-oil equivalent (TOE) of liquid fuels or electricity; $\alpha_{f u e l}^{c a r}$ and $\alpha_{e l e c}^{c a r}$ the average TOE 
consumptions induced by one pkm by car-the fixed costs of car ownership do not enter this trade-off, but are considered in households investments, cf. infra.

Simultaneously, households face a time-budget constraint, which acknowledges the stability of aggregate (average) travel-time budget $T_{m}$ across time and space, at 1.1 hours per person per day. This assumption is supported by numerous studies with fairly close outcomes ranging from 50 minutes to 1.3 hours per day (Zahavi and Talvitie, 1980; Bieber et al., 1994; Schaefer and Victor, 2000; Vilhelmson, 1999). The pkm travelled with each mode add up to $T_{m}$ following:

$$
\sum_{i=1}^{4} \int_{0}^{D_{i}} \frac{d u}{v_{i}\left(u / Q_{i}\right)}=T_{m}
$$

with $v_{i}$ the marginal speed of mode $i$ (the speed of one additional pkm), which depends on the utilisation rate of $Q_{i}$, an index of the pkm capacity of mode $i$, following:

$$
v_{i}\left(D_{i} / Q_{i}\right)=\frac{v_{i 0}}{1+a_{i}\left(D_{i} / Q_{i}\right)^{\varepsilon_{i}}}
$$

The maximum speeds $v_{i 0}$ of the air, private car, public and soft modes are respectively set at 700, 80, 50 and $5 \mathrm{~km} / \mathrm{h}$. The $a_{i}$ and $\varepsilon_{i}$ parameters are calibrated on the mobility and budget share data of 2001, and on the supplementary assumption that saturation $\left(D_{i}=Q_{i}\right)$ drives the speed $v_{i}$ down to $5 \mathrm{~km} / \mathrm{h}$ (for all $i$ $\left.v_{i}(1)=5\right)$. However, in both our REF and OCC scenarios and for any mode $i, Q_{i}$ is assumed to evolve as $D_{i}$, which amounts to considering constant speed for all modes.

\section{Freight mobility demand}

At each simulation year the (short run) cost structure of all productions is assumed to be fixed, following a Leontief production function. In particular, the intensity of all productions in each of three aggregate freight transportation modes (air, water and terrestrial transport, which includes both road and rail modes because of data limitations) is measured by input-output coefficients, which define a linear dependence of current freight mobility to all current production volumes. The input-output coefficients implicitly capture the spatial organisation of the production processes and the constraints imposed on distribution by the distances to markets and the prevalence of just-in-time processes. In both the REF and OCC runs they are exogenously decreased over time $(-0.55 \%$ a year up to 2040 , linearly reduced to $0.35 \%$ in 2050 ) to capture logistic improvements of the production and distribution processes. 


\section{Transportation technologies and energy efficiency}

Following Dargay et al. (2007), the motorisation rate of each region is elastic to per capita disposable income. The variable elasticity quadratically decreases as the motorisation rate increases, from 1.86 at 0 vehicles per capita, to 0.00 at 0.700 vehicles per capita. The consecutive 0.700 vehicles per capita asymptote is derived from the current US equipment rate.

The energy mix and efficiency of private vehicles, i.e. the $\alpha_{\text {fuel }}^{c a r}$ and $\alpha_{\text {elec }}^{c a r}$ coefficients of equation (A.3), result each year from households' decisions on the purchase of new vehicles among 5 car technologies (cf. Table 1 section III.1 above). At each period and in each region, technology $i$ captures a share $\Theta_{i}$ of the market defined by the increase of the motorisation rate and the replacement of all vintages above 15 years. $\Theta_{i}$ is defined by a multinomial logit:

$$
\Theta_{i}=\frac{L C C_{i}^{-\gamma}}{\sum_{j=1}^{5} L C C_{j}^{-\gamma}}
$$

with $L C C_{i}$ the life-cycle cost of technology $i$ computed for the current regional mileage and fuel/electricity prices over a 15-year horizon considering a 13\% discount rate (discussed in Vogt-Schilb et al., 2009); $\gamma$ the 'homogeneity factor', calibrated to maximise the match of the observed and modelled average fleet efficiencies between 2001 and 2005 (in Europe $\gamma$ equals -22). The capital costs of each technology are subject to a $10 \%$ learning curve ( $c f$. endnote 12). For the sole purpose of this curve, all car fleets are supposed to count 100 million vehicles at the starting year, except the efficient hybrids (50 million vehicles) and the electric vehicles (10 million vehicles). These are computational artefacts that allow deriving capital costs trends in line with the available prospective works of authoritative bodies as the IEA (cf. IEA 2006, IEA 2008).

The energy efficiency of modes other than the private car is not represented through explicit vehicle technologies. It is rather implicitly captured through the evolution of the input-output coefficients measuring the intensity of each mode (water, air and terrestrial transport) in automotive fuels and electricity (where applicable):

- The fuel intensity of terrestrial transport is elastic to fuel prices according to a -0.35 elasticity (constant across regions and times).

- The fuel intensity of air transportation benefits from exogenous energy efficiency improvements of $0.7 \%$ a year.

- The fuel intensity of water transportation remains constant at its 2001 calibration level.

- The electricity intensity of terrestrial transport remains constant at its 2001 calibration level (the electricity intensities of the 2 other modes are nil and remain so). 


\section{Biofuel supply curves}

Yearly biofuel supply potentials are interpolated from the 2010, 2030 and 2050 curves published by the IEA (IEA, 2006, pp. 283 and 288). For the sake of clarity, we only reproduce the supply potentials of the biofuel target years 2010 and 2020 (Figure A1, Figure A2). The potential MTOE contribution of biofuels to global fuel demand is determined by comparing the USD per lge production costs in ordinate of each curves with the international producer cost of conventional fuel production; in case carbon pricing is in force this cost is adjusted to account for the carbon emission differential of the fuels - bio-ethanol and bio-diesel are assumed carbon contents $20 \%$ and $10 \%$ below that of the conventional gasolineequivalent. Each macro region is then assumed to consume the produced biofuels prorata its current conventional consumption.

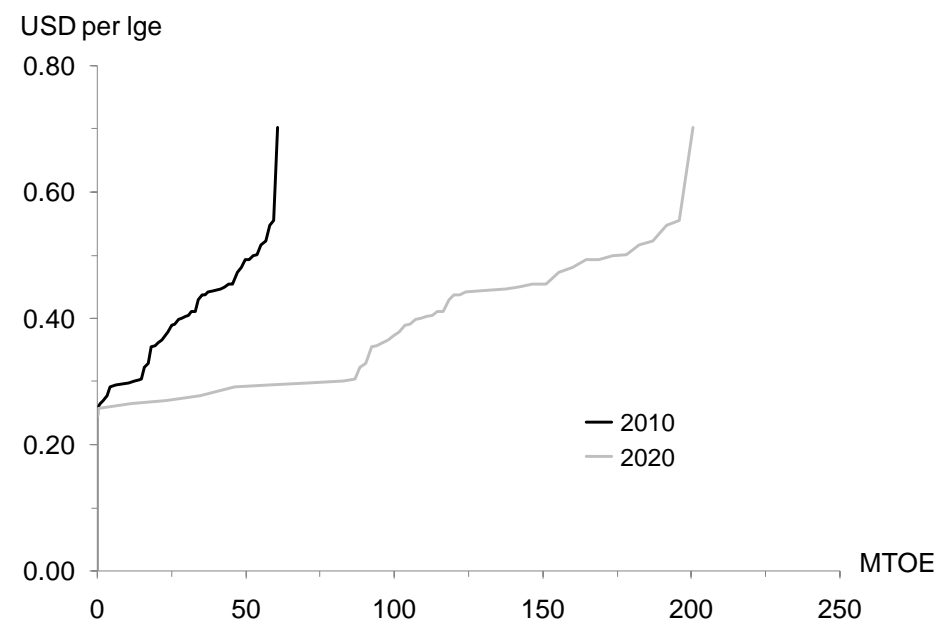

Figure A1. Global supply curve for ethanol biofuels

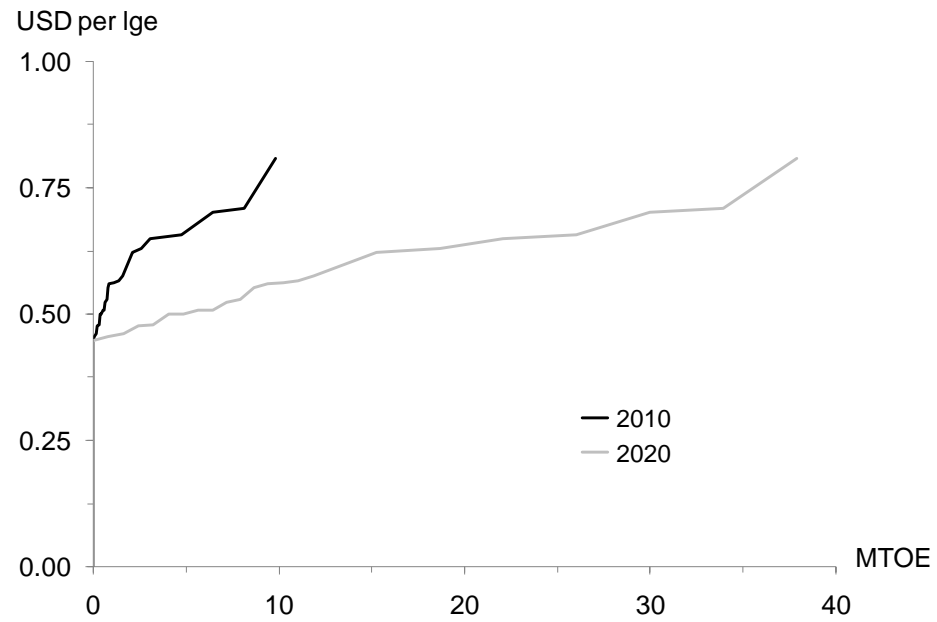

Figure A2. Global supply curve for biodiesel 


\section{Coal-to-liquid substitute}

Beyond the exogenous threshold of 100 year-2001 dollars per barrel of oil, a coal-to-liquid (CTL) substitute to automotive fuels is produced each year based on an imperfect anticipation of the gap between the supply and demand of conventional fuels, on a regional basis. On the supply side, CTL producers perfectly anticipate the increase of the regional conventional refining capacities, and have full information on the global supply curves of biofuel production; however, they wrongly assume maintained utilisation rates of the refining capacities, together with unchanged international average production prices of the conventional fuels and a stable distribution among regions of biofuel production (to anticipate regional biofuel supply). On the demand side, they project aggregate regional demand according to its observed one-year trend. If a shortage of supply results from the crossing of these anticipations, a matching CTL volume is produced.

This volume is sold at a price that is not modelled as such: CTL fuels are not stand-alone goods but are part of the gasoline-equivalent good produced by the refined petroleum products sector. Based on a central 0.7 efficiency assumption (one MTOE of coal is necessary to produce 0.7 MTOE of coal-to-liquid fuel; this efficiency is quite higher than the 0.33 efficiency that can be inferred from current AIE energy balances, but it applies to later years of the projection period), the volume of CTL production impacts on the cost structure of the refining sector through its direct coal costs, and through the higher other primary and secondary factor consumptions induced by the increase of the total gasoline-equivalent output of the sector, considering the prevailing factor intensities. In other words, CTL production is assumed the same cost structure as conventional fuel production, except that coal is substituted to oil as a primary input (on the basis of $1 / 0.7=1.43$ MTOE per MTOE of output).

\section{Endnotes}

\footnotetext{
${ }^{1}$ We restricted our analysis to the less extreme pre-2009 levels for the simple reason that the $-80 \%$ threshold is barred by some of the technical asymptotes built in the current version of IMACLIM-Rwhich are meant to reflect the current state-of-the-art of bottom-up expertise on both intermediate and final energy consumptions. Clarke et al. (2009) provide a discussion of the reasons why extreme abatement targets cannot be achieved by models similar to IMACLIM-R (as the SGM model, which takes part to the study they report on).
} 
${ }^{2}$ Road Transport: Reducing $\mathrm{CO} 2$ emissions from vehicles, European Commission Climate Action: http://ec.europa.eu/clima/policies/transport/vehicles/index en.htm

${ }^{3}$ Congestion occurs because the motorist's private marginal costs diverge from the cost he/she imposes on society. The externalities can manifest themselves as delays in business transactions, excess business and private time lost to congestion, etc.

${ }^{4}$ For instance: severance impacts on ecosystems or communities arising from the construction of a motorway.

${ }^{5}$ The treaty, signed by more than 165 countries, entered into force in February 2005. It commits the countries listed in its Annex 1 to an overall 5.2\% reduction on 1990 levels by 2008-2012, cf.

http://unfccc.int/essential background/kyoto protocol/status of ratification/items/2613.php (accessed December $2^{\text {nd }}, 2011$ ). The EU ratified the treaty in May 2001, committing itself to an $8 \%$ reduction over the period.

${ }^{6}$ In 2006 the EU published a mid-term review of the White Paper on European Transport Policy for 2010 (CEC, 2006). As part of this review, Transport and Mobility in the Catholic University of Leuven developed scenarios to run its TREMOVE model on. This had two aims: firstly to assess the conformance of the transport implementation activities with the original White Paper over the period 2001-2005; secondly, to assess whether the objectives were still feasible given policy and trend developments. An analysis of these 60 objectives is beyond the scope of this research but interested readers are directed to Annex 1 of the 2001 White Paper on Transport (CEC, 2001a).

${ }^{7}$ A global dimension has also been added to the policymaking process with the adoption of the 2002 strategy on establishing a global partnership in sustainable development (CEC, 2002): http://eurlex.europa.eu/LexUriServ/site/en/com/2002/com2002 0082en01.pdf

${ }^{8}$ This strengthened the commitment in the original SDS, outlined in relative terms only: to reduce atmospheric greenhouse gas emissions by an average of 1\% of 1990 levels per year up to 2020.

${ }^{9}$ Cf. EC regulation 443/2009 at http://eur-

lex.europa.eu/LexUriServ/LexUriServ.do?uri=OJ:L:2009:140:0001:0015:EN:PDF (accessed December $\left.13^{\text {th }}, 2011\right)$.

${ }^{10}$ The following technology description is adapted from Vogt-Schilb et al. (2009).

${ }^{11}$ Vogt-Schilb et al. (2009) provide more detail on the calibration process, and the assumptions backing the more debatable characteristics of the hybrid and electric technologies. 
12 The 'learning curve' approach to technology improvements dates back to Arrow (1962). A 10\% rate means that the capital cost of a technology decreases by $10 \%$ every time the fleet of that technology doubles. An anonymous reviewer suggested that the learning rates of the hybrid and electric cars should be somehow correlated, because they share the same battery technology. Unfortunately, we could not confirm and implement such linkages within the timeframe of this publication; we will consider this issue in future work.

${ }^{13}$ The higher bounds to energy and carbon efficiency of the conventional and hybrid technologies defined by their efficient versions may appear high, but (i) must be understood as fleet averages: more efficient cars do already exist, but for sizes, performances and equipments that cannot match the needs of all drivers, especially when it comes to long-distance trips (less efficient cars thus tend to drive more annual miles than more efficient ones, which impacts on average efficiency); (ii) are the on-road values that are explicitly implemented in IMACLIM, notoriously higher than bench-test values. Throughout this research we systematically assess the corresponding bench-test values as $18 \%$ lower, based on an assessment of the average bench-test emissions of the 2005 fleet by the Sustainable Mobility Project ( $c f$. http://www.wbcsd.org/work-program/sector-projects/mobility.aspx). At last, it must be borne in mind that carbon intensities can be cut down by the penetration of biofuels.

${ }^{14}$ Following the IEA (IEA, 2004), net carbon emissions of bio-ethanol and bio-diesel consumptions are set at $20 \%$ and $10 \%$ those of the average conventional fuel.

${ }^{15}$ Rozenberg et al. (2010) provide more detail on biofuel and CTL modelling in IMACLIM-R.

${ }^{16}$ For the sake of brevity the results of the 12 regions of IMACLIM-R will systematically be grouped into 5 regional aggregates. Although, the "Europe" region of IMACLIM-R extends to all geographical Europe, i.e. beyond the European Union strictly speaking, the size and economic characteristics (including transportation organization) of non-EU Europe relative to EU Europe are such that this can be overlooked.

${ }^{17}$ All dollar figures are in year 2001 USD.

${ }^{18}$ Oil supply is endogenous in IMACLIM-R. Each region is endowed with 6 types of reserves differentiated by their extraction costs. The effective capacity of production in each of these 6 reserves follows a Hubbert curve. It is exploited on a simple profitability criterion, based on a mark-up rate that increases with current output (Waisman et al., 2012).

${ }^{19}$ Because IMACLIM-R is a simulation model and not an optimisation one, the 2020 and 2050 constraints cannot be set as such. Rather, the European emission trajectory is obtained by a trial-and-error 
approach that consists in adjusting 4 decadal slopes of increase of the carbon price in Europe. The $c a$. $10 \%$ overshoot at both dates was willingly not refined as it happens to strengthen the argument of the paper.

${ }^{20}$ We do not model the moderate European Trading System prices from 2005 to 2010 because these do not concern transportation activities. Accounting for them could only reinforce our conclusions, by putting a downward pressure on the post-2010 carbon prices necessary to the overarching commitments leading to even weaker impacts of compliance with the overarching targets on transportation activities. ${ }^{21}$ The IMACLIM-R model is not specifically calibrated to reproduce the recent economic cycles, namely the 2005 to 2008 boom and the ensuing crisis. This accounts for its not projecting oil prices consistent with observation over these years.

${ }^{22}$ The penetration of electric vehicles is substantially lower than the figures commonly found in recent studies (cf. e.g. IEA, 2009), for the reason that, contrary to these studies, OCC does not assume any targeted incentive or support.

${ }^{23}$ This second target has only been formulated in 2007 (CEU, 2007), in a political context marked by a hot debate on the actual sustainability of biofuel production when due consideration is given to its impacts on biodiversity, water consumption, land and hence food prices, etc.

${ }^{24}$ The initial SDS emission target for 2012 has since been postponed to 2015 (cf. EC regulation 443/2009 at

http://eur-lex.europa.eu/LexUriServ/LexUriServ.do?uri=OJ:L:2009:140:0001:0015:EN:PDF, accessed December $\left.13^{\text {th }}, 2011\right)$. 